\title{
Expressões artísticas na educação: um desafio ao nível do desenvolvimento do aluno
}

\author{
Maria José dos Santos Cunha \\ Departamento de Educação e Psicologia, Universidade de Trás-os-Montes e Alto Douro, Portugal
}

\begin{abstract}
Resumo
A educação através das diferentes expressões traduzse em processos integrados e abrangentes no sentido do desenvolvimento do ser humano e nas suas múltiplas dimensões de formação, razão para que a educação e as expressões artísticas possam encetar uma caminhada conjunta e comungar de objetivos comuns em prol da educação dos indivíduos, na medida em que esta união justifica uma melhor aprendizagem, já que motiva uma mais firme articulação entre os conteúdos teóricos e práticos, entre as experiências de formação qualificante e as de formação experiencial. Seguindo estes pressupostos, pretendemos delinear um projeto educativo, assente na metodologia de projeto de aprendizagem, que nos parece ser útil no desenvolvimento de competências e habilidades básicas importantes para os nele implicados.
\end{abstract}

Palavras chave: educação, desenvolvimento, expressões artísticas.

\section{Introdução}

O cultivo de diferentes modos de expressão artística é um recurso educativo precioso. As expressões artísticas - porque são experiências vivas e criativas - ajudam a explorar, a aprender e reagir aos estímulos do meio envolvente e têm a capacidade para provocar o conhecimento de novas realidades e conduzir à reflexão social, porque promovem a transmissão de valores sociais, ajudam a remover as barreiras artificiais entre os indivíduos, propiciam oportunidades de tecer laços entre diferentes áreas temáticas e atuam como elemento catalizador nestes processos. Pelas razões apontadas, as expressões artísticas conferem aos que nelas se implicam, a possibilidade de se desenvolverem afetiva, social e intelectualmente e, com isso, aprenderem a interpretar o mundo, a estruturar o pensamento, a desenvolver o equilíbrio emocional, a formar o caráter e a afirmar a sua identidade. Assim sendo e porque a escola de hoje tem por objetivo uma outra fundamentação educacional e formativa e uma necessidade de mudança de paradigma que encaminhe para uma formação que proporcione - além do desenvolvimento das chamadas competências técnicas - um conjunto de competências transversais e sociais, justifica-se a sua aposta nas expressões artísticas, nas suas variadíssimas formas. Aposta que deve ter em conta que as expressões artísticas são meios que possibilitam promover nos indivíduos, não apenas capacidades, qualidades pessoais, o sentido da responsabilidade, a flexibilidade e a criatividade, ou seja, o desenvolvimento integral de si próprios e os torne abertos à mudança, mas também competências que irão, por certo, reforçar a bagagem, não apenas daqueles que possuem já um conjunto de dons inatos, mas tornará todos mais aptos à construção de respostas às mutações decorrentes de uma sociedade assente no conhecimento.

É assim nosso propósito, apresentar neste artigo as linhas orientadoras de um projeto educativo, assente na metodologia de projeto de aprendizagem, denominado Espaço de Arte Criativa, a desenvolver por alunos do mestrado em ensino de educação pré-escolar e $1^{\circ}$ ciclo do ensino básico da UTAD, no âmbito da unidade curricular de teoria e técnicas de criatividade e destinado a crianças destes níveis de ensino. Com esse projeto pretendemos desafiar o desenvolvimento destes alunos do ensino superior, ao proporcionar-lhes uma forma inovadora de abordarem, compreenderem e assimilarem conteúdos fundamentais para a sua vivência profissional futura e, em simultâneo, contribuir para o desenvolvimento dos mais novos a quem o mesmo é destinado, bem como estabelecer elos de ligação com a comunidade educativa e comunidade em geral.

\section{A educação através das diferentes expressões}

O homem desde sempre estabeleceu uma forte aliança com a arte, uma vez que esta está associada à sua capacidade de expressão e à sua liberdade criativa. A arte está ligada ao sentir e ao prazer e estes elementos fazem parte da essência humana.

É na arte, cuja origem está no próprio homem - ser essencialmente social e cultural - que o homem canaliza as suas energias produtivas. Estas energias do homem podem manifestar-se das mais diferentes formas, mas resultam sempre na criação de produtos culturais e artísticos.

$\mathrm{O}$ apelo que tem sido feito nos últimos anos à utilização das diferentes expressões, constitui prova de que a educação e as expressões artísticas podem encetar uma caminhada conjunta e comungar de objetivos comuns em prol da educação dos indivíduos. Essa união justifica, ainda, uma mais firme articulação entre os conteúdos teóricos e práticos, entre as experiências de formação qualificante e as de formação experiencial. Isto porque, a educação através das diferentes expressões não consiste numa mera transmissão de informação, nem depende de um dom. Ela traduz-se, na realidade, em processos integrados e abrangentes no 
sentido do desenvolvimento do ser humano, nas suas múltiplas dimensões de formação e no romper com a lógica da fragmentação dos saberes. A apreensão destas formas de comunicação, segundo Marques e Sousa (2008: 9),

(...) deve ser entendida como um sistema de símbolos e uma manifestação cultural, cujo objectivo se centra em diferentes modos de ler o mundo e de o questionar. Assim, para que tal finalidade seja atingida, torna-se necessário conhecer e compreender os códigos que as várias manifestações artísticas pressupõem.

As expressões artísticas dão prazer e sentido à vida e afirmam que a partilha da criação artística pode fortalecer o "eu" de cada um e abrir, em simultâneo, o caminho para a aprendizagem de todos os tipos de saberes e destrezas, incluindo os mais racionais e formais da escolaridade (Trevarthen, 2008). Assim acontece com a expressão visual, uma pedagogia ativa que permite ao aluno compreender o universo visual e social que o rodeia e pôr em prática e amadurecer as suas competências. Traduz-se esta expressão, na ópticade Duarte (2007), num conjunto de aprendizagens centradas no desenvolvimento de competências orientadas para o domínio da análise e leitura crítica do entorno visual; para a educação estética; para a criação de produtos artísticos ou de outros que se enquadram na cultura visual e, ainda, para uma educação que promova a intervenção cívica. Educar, neste âmbito, implica dotar o educando das ferramentas necessárias para que se torne num observador atento, crítico e um agente interventivo na realidade circundante, pressupõe - para além dos momentos lúdicos, de prazer e de expressão pessoal que se vivem - o desenvolvimento de uma percepção visual, de uma análise mais profunda e mais analítica do entorno. Outra das expressões artísticas, muito vulgarizadas, é a expressão dramática, que Bento (2003) entende ser uma atividade pré-teatral, na medida em que a sua finalidade não é apresentar um espectáculo. De facto, a expressão dramática não é teatro e os objetivos desta forma de expressão, apostada na formação pessoal do aluno, no desenvolvimento das suas capacidades de relacionamento interpessoal, da sua criatividade e espírito crítico, passam, unicamente, por fomentar o espírito artístico e o prazer da descoberta.

É através de atividades de experimentação e criação artística, num trabalho físico e de valorização da inteligência emocional e sensível, que a expressão dramática se pode levar a cabo, nomeadamente quando se tem como objetivos fundamentais o desenvolvimento da expressão individual do aluno e da sua competência comunicativa. O recurso a esta forma de expressão permite criar uma maior disponibilidade física e psicológica, melhorar a postura corporal, a flexibilidade, a expressividade de movimentos e os gestos. Desenvolve, ainda, a criatividade, a expressividade, a competência comunicativa e a aprendizagem global, nomeadamente, a cognitiva, a afectiva, a sensorial, a motora e a estética.

A expressão corporal, expressão que se desenvolve em atitudes de confiança na forma como cada um se movimenta e desloca no espaço, é um outro modo de expressão artística, que utiliza o corpo como instrumento de comunicação do homem no mundo e que permite exprimir o pensamento e criar. Ferraz afirma que "a possibilidade de apreender o estímulo para a aprendizagem através do seu próprio corpo, dos seus sentidos, de entrar em contato com a sua experiência corporal intensifica o processo de integração dos conteúdos relevantes para a estruturação do conhecimento e consequentemente para a aprendizagem" (2011: 70). De facto, quando se trabalha a expressão corporal, esta produz, no dizer de Calazans (2003: 13),

(...) um processo de autoconhecimento e de criatividade por meio do qual cada indivíduo que nele se integra se pode preparar para estar mais bem situado face aos fenómenos intrínsecos e extrínsecos à natureza e transformações estruturais - vivenciadas no desenvolvimento da sociedade, numa vigorosa (re)construção do homem.

Esta reeducação do corpo vai, aos poucos, trazendo consigo a integração entre o que pensamos, sentimos e expressamos e possibilita redescobrirmo-nos.

A educação musical, expressão artística que contribui para uma harmonia corporal e afetiva, desenvolve, nos que a praticam, sentimentos coletivos e de autocontrole, disciplina os movimentos do corpo, gestos e atitudes. A música envolve o corpo e a mente, o sentimento do "eu" e a compreensão dos outros. Fazer música implica construir canais de comunicação, dar condições de descoberta, abrir caminhos para as emoções evoluírem e se desenvolverem. O envolvimento nessas experiências de construção faz parte da educação da inteligência, da sensibilidade e dos afetos e leva à melhoria da acuidade auditiva, ao aprimoramento e ampliação da coordenação viso-motora, das capacidades de compreensão, interpretação e raciocínio, à descoberta da relação com o meio em que se vive, ao desenvolvimento da expressão corporal e da linguagem oral. Pelas inúmeras oportunidades que as atividades musicais podem oferecer, é previsível que projetos de trabalho que as incluam, viabilizem novos rumos e novas práticas para a educação.

Muitas outras expressões artísticas poderiam ser abordadas para além das focadas, com a certeza de que todas elas poderão ser contributos válidos para a educação. Estamos, no entanto, convictos de que o exercício de educar exige conhecimento, planeamento adequado e coerência e que esse exercício deve ser continuado e traduzir-se em experiências significativas, de modo a permitir uma melhor compreensão e construção de um conhecimento significativo.

\section{O processo de ensino aprendizagem: um desafio da contemporaneidade}

$\mathrm{Na}$ época em que vivemos - um contexto de globalização económica e de novas formas de organização da produção do trabalho e de crescentes processos de democratização da sociedade - o ritmo dos acontecimentos é de tal ordem, que é frequente 
verificarem-se, em dois ou três anos, mutações que no passado demoravam algumas décadas. As mudanças imprevisíveis, profundas, generalizadas, ocorrem num ritmo veloz, são irreversíveis, fazem parte da nossa vida e abrangem todas as áreas da atividade humana. Neste contexto, também a aprendizagem, processo através do qual o indivíduo sobrevive e evolui num mundo em constante transformação, é assunto central da sociedade atual. Por outro lado, o sucesso de cada um depende não apenas da sua inteligência, empenhamento e espírito de trabalho, sendo fundamentais à aquisição desse sucesso, como resultado de um equilíbrio entre a inteligência "emocional" e a "intelectual" muitos outros fatores como: as relações interpessoais, a capacidade de trabalho em grupo, a capacidade de ouvir e de se colocar na posição dos outros, assim como a capacidade de ouvir a própria consciência. Nesta aquisição, a aprendizagem e a educação são, cada vez mais, entendidas como uma condição necessária para atingir o sucesso, uma vez que no dizer de Ferreira (2007: 21), "indivíduo ou organização que descure os seus saberes, contenha a sua curiosidade e paralise as suas condutas, mantendo-se hoje como ontem e amanhã como hoje, está a pôr em perigo a sua sobrevivência e credibilidade". E porque o homem no contexto atual em que a vida é um processo contínuo de adaptação a situações novas e diferentes - tem desde cedo, de alargar os horizontes da sua acção, o ensino tem de mudar e não se limitar apenas

(...) à exposição teórica da matéria de que se trata, sintetizando conceitos, ideias, teorias ou doutrinas, ou esclarecendo e exemplificando a sua aplicação prática, mas serve também para desenvolver a mente do estudante, fomentando a sua habilidade para o raciocínio ou faculdades de relação, promovendo o seu espírito crítico e desenvolvendo a sua capacidade de síntese (Martín, 2010: 17).

Trata-se antes, de encaminhar para uma formação que proporcione, além do desenvolvimento das chamadas competências técnicas, um conjunto de competências transversais e sociais, que promovam nos indivíduos: capacidades, qualidades pessoais, o sentido da responsabilidade, a flexibilidade e a criatividade, ou seja, o desenvolvimento integral de si próprios e os torne abertos à mudança. Mudança, que no dizer de Escribano e DelValle (2010: 135), "não significa rutura drástica com o que existia, trata-se simplesmente de completar a aquisição de conteúdos com o desenvolvimento de habilidades, capacidades e atitudes indispensáveis no mundo atual", mas antes requer, tendo em vista um ensino de qualidade, capaz de atender às exigências da contemporaneidade, marcada pela multiculturalidade, complexidade, constante avanço científico e processos de permanente mudança, um esforço no ajudar a incentivar e motivar o aluno para as tarefas, permitindo, desta forma, que os produtos resultantes da aprendizagem vão ao encontro dos resultados por ele esperados. Mas porque o processo de ensino aprendizagem é hoje mais exigentes, não basta, por isso, colocar os conteúdos nas aulas. É também e sobretudo necessário, estimular a interatividade dos alunos tendo em vista o desenvolvimento de competências cognitivas, emocionais, sociais, instrumentais e outras - nos diferentes ciclos formativos - como preparação para que possam atuar de forma eficiente em todos os âmbitos da vida e isso consegue-se em parte, recorrendo às expressões artísticas, discussões e jogos pedagógicos, que lhes proporcionam uma melhor adaptação às mudanças que se produzem na sociedade. Até porque, como salienta Martins, Fernandes e Palha (2000), toda a criança que seja estimulada a desenvolver caminhos próprios de expressão, partindo do conhecimento, de materiais, de técnicas e de conceitos nas diferentes áreas de expressão, possui capacidade para participar de modo mais efetivo no seu contexto sociocultural, contribuindo produtivamente e transformando o seu desenvolvimento num processo contínuo de aprendizagens e de reconstrução de modos de expressão.

De uma forma global, pode dizer-se que as atividades dramáticas proporcionam oportunidades para alargar a experiência de vida dos alunos e enriquecer as suas capacidades de decisão e escolha, sendo suscetíveis de gerar reflexões sobre valores e atitudes. As expressões dramáticas proporcionam, ainda, formas e meios expressivos para explorar temas e conteúdos de aprendizagem que estão articulados com outras áreas disciplinares, tornando-se - por todas estas razões essenciais - numa educação que propicie não apenas conhecimentos, mas que dote os indivíduos das competências necessárias que lhe permitam ser capazes de aceder aos conhecimentos que, em cada momento do seu trajeto de vida se tornem necessários.

\section{O projeto educativo delineado}

Na realidade, o projeto - uma intenção que estrutura metódica e progressivamente a realidade futura - é um dos procedimentos mais úteis para quem se implica no âmbito das intervenções socioculturais e educativas. Para o elaborar não existem normas rígidas, mas apenas instrumentos que ajudam a organizar as ideias, a precisar os objetivos e a concretizar as atividades específicas. No caso presente escolheu-se uma metodologia de "projeto de aprendizagem", que se assume como uma metodologia de prática real, efetuada em função da programação e dos objetivos que, com a unidade curricular, se pretendem alcançar no processo de ensino/aprendizagem.

O projeto de aprendizagem é útil no desenvolvimento de competências e habilidades básicas importantes, para que os nele implicados possam viver vidas autónomas, produtivas e responsáveis, na medida em que: procura evitar que a aprendizagem se torne algo passivo, puramente verbal e teórico, e, por conseguinte, desinteressante; em que abre espaço à participação ativa, não apenas na concepção e elaboração dos projetos, mas também na sua implementação e avaliação e, ainda, porque torna a aprendizagem ativa $\mathrm{e}$ significativa, dado ser um fazer real mais do que um mero assimilar.

O aprender neste processo é o mais relevante, secundarizando-se o processo de ensino, para que a 
aprendizagem se desenvolva da melhor forma. Os alunos adquirirem uma postura diferente, capacitam-se para gerir inércias, mobilizarem parcerias e ultrapassarem dificuldades que, em princípio, os poderiam desviar dos seus reais objetivos, mas que com a experiência se convertem em energias incentivadoras e desafiantes das suas capacidades, sem nunca porem de parte a criatividade, elemento essencial num curso desta natureza. Além disso, ao conceberem, gerirem e avaliarem projetos, os alunos passam de consumidores a produtores de conhecimento. É que, tal como refere Justino (2010: 84), "mais do que aprender a fazer, as aprendizagens têm de orientar-se para o aprender a pensar". Este aproximar da realidade, leva a que os alunos se sintam protagonistas e implicados e possam identificar o trabalho que desenvolveram com o trabalho que poderão vir a desenvolver no futuro.

A primeira decisão a tomar foi solicitar aos alunos da turma que, de forma espontânea, constituíssem três grupos de trabalho e informá-los que cada grupo deveria, no âmbito da unidade curricular lecionada, delinear intervenções sob a forma de ateliês. Na opinião de Sanches González (2010: 25),

\section{Esta forma de constituição dos grupos apresenta a vantagem de proporcionar equipas com fraca conflitualidade, uma vez que, normalmente, os alunos escolhem agrupar-se com aqueles com quem sentem maior afinidade. Por outro lado, na medida em que são os próprios a constituírem-se como grupo, o nível de responsabilidade que assumem relativamente aos resultados é geralmente maior que nas restantes modalidades de constituição.}

Após a constituição dos grupos houve lugar a uma reflexão sobre o conceito de ateliê e foram facultadas aos alunos indicações claras e precisas acerca dos passos a ter em conta na sua elaboração.

Cada grupo deveria assim selecionar os objetivos do seu ateliê, os conteúdos, estratégias e atividades a desenvolver, os recursos materiais e humanos necessários para o efeito. Deveria ainda indicar a forma como o trabalho seria avaliado. Mas porque as intervenções que pretendam promover experiências formativas a partir dos conhecimentos proporcionados, devem também "cuidar dos critérios da sua avaliação, atendendo a que todos os passos neste processo proporcionem a necessária autonomia em qualquer aprendizagem e ainda a fortaleçam (Rué, 2009: 111), foi negociado com os alunos o sistema de avaliação.

Cada grupo de trabalho delineou alguns ateliês. Um desses ateliês integrava: a arte do origami; a expressão plástica e a arte através do balão. Outro destinava-se a: aprender, fazer e criar com plasticina; culinária criativa e criar e reciclar. O terceiro, abrangia as artes mágicas; experiências científicas e a feitura de cataventos criativos.

Procurava-se com a experiência apostar numa educação mais ativa, libertadora, cooperativa e holística, que permitisse aos alunos do ensino superior: enfrentar algumas das dificuldades com que se irão debater futuramente na sua profissão, uma aproximação, convivência e cooperação com as pessoas e pensarem a aprendizagem como um crescimento e desenvolvimento contínuo, onde a troca com o meio e as comunidades, são uma constante que torna a educação mais viva. Por outro lado, pretendia-se que com o desenvolvimento doestetrabalho pudessem dar asas à sua imaginação e criatividade, de forma a cativarem os mais pequenos, que se sentirão por certo mais motivados, quando implicados na feitura de coisas novas, que os ajudam a partilhar o que sentem.

\section{Conclusão}

A educação dos indivíduos tem hoje um âmbito mais alargado, dado que estão em causa objetivos de aprendizagem globais onde se integram aprendizagens de competências transversais aos vários domínios da vida do indivíduo, desde académicas até competências de cidadania. Assim e com a finalidade de conseguir garantir aprendizagens mais eficazes, compete à escola selecionar pontualmente técnicas, recursos ou dinâmicas ligadas e envolvidas diretamente com os objetivos que se pretendem alcançar, ou sejam, os de desenvolver todas as potencialidades do ser humano que aspira ser plenamente ele próprio em todos os domínios e a construir a sua transformação. $\mathrm{Na}$ verdade, são os desejos do ser humano que dão sentido às suas aspirações e fazem com que utilize as suas energias nas direções mais diversificadas. À partida, como salienta Ferreira (2007), ele não é autónomo, pode conseguir a autonomia; ele não tem a posse de si mesmo, mas pode atingi-la; ele não é livre, pode, contudo, atingir a liberdade de espírito; ele não é competente, mas pode tornar-se competente; em suma, ele não é sujeito, mas pode vir a sê-lo. E porque a escola deve ser cada vez mais local de sensibilização e consciencialização para uma pedagogia da expressividade e da criatividade, da comunicabilidade e sociabilidade tão necessárias num mundo globalizado, ela deve recorrer às expressões artísticas, dando a cada um a oportunidade de escolher os seus percursos, para que num contexto marcado pela inovação e imprevisibilidade dos acontecimentos como o atual, possa adquirir competências e desenvolver capacidades que ajudem a lidar com os desafios que doravante nos são colocados. Não se pode é deixar que a passividade se apodere de nós, pois o que agora não pode concretizar-se, na altura certa pode conseguir-se e como tudo na vida, há um verso e um reverso. Assim sendo, torna-se necessário apostar em processos e não apenas em produtos, em trajetos e não apenas em metas, que nos permitam encontrar outras formas de organizar e viver a escola, o ensino e a aprendizagem, sendo que uma dessas formas, em nosso entendimento, é o recurso às expressões artísticas.

\section{Referências}

Bento, A. (2003). Teatro e animação. Outros percursos de desenvolvimento sócio-cultural no Alto Alentejo. Portalegre: Edições Colibri.

Calazans, J. (2003). Tempos de trabalho corporal com Angel Vianna. In Julieta Calazans, Jacyan Castilho \& 


\section{EXPRESSÕES ARTÍSTICAS NA EDUCAÇÃO}

Simone Gomes (coords.). Dança e educação em movimento (pp. 11-179). São Paulo: Cortez.

Duarte, R. A. P. (2007). Educação Visual para a cidadania: um estudo comparativo em contexto escolar. Tese de Doutoramento na Área Científica de Comunicação Visual e Expressão Plástica. Braga: Universidade do Minho.

Escribano, A. \& Del Valle, A. (coords.) (2010). El aprendizaje basado en problemas. Una propuesta metodológica en educación superior. Madrid: Narcea Ediciones.

Ferraz, M. (coord.) (2011). Educação Expressiva: um Novo Paradigma Educativo. Lisboa: Tuttirév Editorial.

Ferreira, P. T. (2007). Guia do animador na formação de adultos. Barcarena: Editorial Presença.

Justino, D. (2010). Difícil é educá-los. Lisboa: Fundação Francisco Manuel dos Santos.
Marques, E. \& Sousa, P. (2008). Tecnologias para quê? In Infância na Europa, 14, 7-9.

Martín, I. Z. (2010). La lección magistral. In Maria Paz Sánchez González (coord.), Técnicas docentes y sistemas de evaluación en educación superior (pp. 1722). Madrid: Narcea Ediciones.

Martins, A., Fernandes, A. \& Palha, M. (2000). Síndrome de Asperger - revisão teórica. In Acta Pediátrica Portuguesa $\mathrm{n}^{\circ}$ 1, vol. 31, 47-53. Lisboa: Clínica Universitária de Pediatria Hospital de Santa Maria.

Rué, J. (2009). El aprendizaje autónomo en educación superior. Madrid: Narcea Ediciones.

Sánchez González, M. P. (coord.) (2010). Técnicas docentes y sistemas de evaluación en educación superior. Madrid: Narcea Ediciones

Trevarthen, C. (2008). Valorizar a arte criativa na infância. In Infância na Europa, 14, 11-14. 